\title{
OS MOTIVOS DA CENSURA EM FELIZ ANO NOVO, DE RUBEM FONSECA
}

Deivis Jhones Garlet ${ }^{1}$

Resumo: Ao considerar como premissa a relação existente entre literatura e história, necessariamente enfatizamos o diálogo entre ambas, no qual elementos extraestéticos constituintes do meio ideológico que circunda o escritor em dado momento são transmutados no ato estético para o interior do plano narrativo, por meio das operações de reflexo e de refração, passando por uma avaliação axiológica e desempenhando uma determinada função estética e, em retorno, uma dialogicidade com o contexto material. É com esse entendimento que propomos uma análise do conto Feliz Ano Novo, de Rubem Fonseca, que foi censurado pela Ditadura Civil-Militar em 1975. O objetivo consiste em construir, com o recurso de conceitos do Círculo de Bakhtin e das leis sobre censura da época, uma explicação dos motivos que podem ter levado ao corte da narrativa, salientando-se o matiz explicativo, mas não justificativo. Entendemos que esse estudo contribui para a compreensão da ideologia da Ditadura Civil-Militar e do contraponto simbólico efetuado no fazer artístico de Rubem Fonseca. Além disso, ao estudarmos a especificidade do literário em consonância com outros ramos do saber, como a história, a ciência política e a jurídica, inscrevemos nosso trabalho no âmbito maior dos estudos comparados em literatura, sempre tendo no horizonte como paradigma o diálogo nas relações do fazer humano.

Palavras-chave: História. Literatura. Ditadura Civil-Militar. Censura.

Abstract: When considering the premise of the relationship between literature and history, necessarily emphasize the dialogue between the two, in which extraestéticos constituent elements of the ideological environment that surrounds the writer at any given time are transmuted in the aesthetic act into the narrative level, through the operations reflection and refraction, through an axiological assessment and playing a certain aesthetic function, and return a dialogicity with the material context. It is with this understanding that we propose an analysis of the tale Feliz Ano Novo, Rubem Fonseca, who was censured by the Civil-Military Dictatorship in 1975. The goal is to construct, with the concepts of resource Bakhtin Circle and the laws on censorship time, an explanation of the reasons that may have led to the narrative of the court, emphasizing the explanatory hue, but not justification. We believe that this study contributes to the understanding of the ideology of Civil-Military Dictatorship and symbolic counterpoint made in artistic make Rubem Fonseca. In addition, by studying the literary specificity in line with other branches of knowledge, such as history, political science and legal, signed up our work in the greater context of comparative studies in literature, having always on the horizon as a paradigm dialogue in relations human do.

\footnotetext{
${ }^{1}$ Doutorando em Estudos Literários do Programa de Pós-Graduação em Letras da UFSM.
} 
Keywords: History. Literature. Civil-Military Dictatorship. Censorship.

O estudo literário, com exigências científicas, tradicionalmente é materializado em um modelo pré-definido. Anuncia-se o objeto de pesquisa, o objetivo, a teoria e a metodologia em uma articulação sintática cadenciada pela lógica. Então, passa-se ao texto literário em si. Sem menosprezar ou questionar a eficácia de tal paradigma, queremos, todavia, pedir vênia para infringirmos a regra, afinal trabalhamos com a literatura, um locus marcado indelevelmente pela criatividade. Que nos seja permitida, então, uma centelha de poiese na forma para expor o conteúdo, sem prejuízo de avaliação pelos pares (e pelos ímpares). Concedamos voz imediatamente ao objeto de análise:

\footnotetext{
Atirei bem no meio do peito dele, esvaziando os dois canos, aquele tremendo trovão. O impacto jogou o cara com força contra a parede. Ele foi escorregando lentamente e ficou sentado no chão. No peito dele tinha um buraco que dava para colocar um panetone. (Fonseca, 2005, p. 19)
}

O excerto narrativo, pertencente ao conto Feliz Ano Novo, de Rubem Fonseca, permite a percepção do uso de uma linguagem direta, articuladora de uma mimese ao estilo realista, sem experimentalismo formal. A cena expõe um assassinato violento por meio de um tom de normalidade, como algo prosaico, lúdico inclusive, como a referência ao "panetone" em sugestão ao tamanho do buraco aberto no peito do assassinado pela descarga da arma. Através deste excerto, podemos compreender a estreita relação entre a forma e o conteúdo, articulando uma posição de crítica à violência, tão banalizada que não causa espanto, perplexidade. Com esse entendimento, rechaçamos a priori qualquer possibilidade de compreensão do texto pelo viés de uma apologia da violência, antes exatamente o contrário.

A violência, sobremodo a urbana, de fato constitui o leitmotiv de Feliz Ano Novo, tanto do conto, quanto da coletânea de título homônimo. Um leitmotiv que instala, ao lado da organização formal de matiz realista, uma posição axiológica no universo ficcional e, em diálogo, com a realidade concreta, a saber, a crítica à banalização da violência. 
Considerando-se como paradigma a relação entre a literatura e o contexto de produção, entendemos que o escritor de Feliz Ano Novo incorpora à narrativa, de maneira estetizada, elementos extraestéticos do mundo circundante, como a gratuidade da violência, e posiciona-se criticamente na escolha do tema e da forma de realizá-lo. Em acordo com o pensamento de Candido (2010), o externo se torna interno, passando a funcionar de maneira específica no interior da narrativa.

Assim, a violência tornada prosaica na sociedade é refletida e refratada no ato estético, permanecendo seu traço cotidiano, mas instalando uma posição axiológica de desacordo, sobremaneira na forma lexical escolhida para representar a mesma. Em outras palavras, a narrativa procura chocar e instigar à reflexão precisamente através da forma com que apresenta o conteúdo, construindo então uma posição de contestação ao senso comum. Evidentemente, o autor labora em sua criação artística com objetos-signo que o circundam, como a violência gratuita, ou seja, com o meio ideológico, assim definido por Medviédev:

O homem social está rodeado de fenômenos ideológicos, de "objetossigno" dos mais diversos tipos e categorias: de palavras realizadas nas suas mais diversas formas, pronunciadas, escritas e outras; de afirmações científicas; de símbolos crenças religiosas; de obras de arte, e assim por diante. Tudo isso em seu conjunto constitui o meio ideológico que envolve o homem por todos os lados em um círculo denso. Precisamente nesse meio vive e se desenvolve sua consciência. A consciência humana não toca a existência diretamente, mas através do mundo ideológico que a rodeia. (Medviédev, 2012, p. 56)

O meio ideológico no qual Rubem Fonseca está imerso ao criar Feliz Ano Novo é a Ditadura Civil-Militar (1964-1985), caracterizada pelo autoritarismo, pela violência e pela censura, orientadas pela Doutrina de Segurança Nacional, a qual prevê o combate aos supostos subversivos como uma meta imprescindível, conforme podemos ler em Comblin (1978). De acordo com a Doutrina, todas as medidas arbitrárias eram necessárias para o combate ao perigo comunista, avalizando, então, sob a ótica governamental, a tortura e a censura, e criando - especialmente após o Ato Institucional $n^{\circ} 5$, de 1968 - uma "cultura do medo", segundo Alves (1985), na qual todos eram potenciais subversivos. Ao mesmo tempo, em sua diretriz econômica, a 
Doutrina previa o desenvolvimento do capitalismo associado e dependente do estrangeiro, aprofundando as desigualdades sociais, de acordo com Gaspari (2002).

A narrativa objeto de análise deste estudo integra a coletânea intitulada Feliz Ano Novo, a qual se compõe de 15 contos em que a violência urbana ocupa posição destacada. No ano de sua publicação, 1975, foi totalmente censurada pelo Departamento de Polícia Federal sob a alegação de "exteriorizar matéria contrária à moral e aos bons costumes", conforme podemos ler na contracapa da edição de 2005. Desde então, esta explicação para a censura da obra tornou-se um axioma. Todavia, nos indagamos: em que consistia esta "matéria contrária à moral e aos bons costumes"? Como ela é representada no texto literário? Em suma, por que, exatamente e não de forma subjetiva, houve a censura sobre a obra?

Partindo dessa inquietação, elegemos o conto Feliz Ano Novo para efetuar uma possível leitura dos motivos que levaram ao corte do mesmo pelas autoridades, deixando indicada a plausibilidade de extensão do estudo aos demais contos da obra.

A narrativa, como constatamos anteriormente, é permeada pela temática da violência urbana. Porém, apenas a representação literária da violência não constitui motivo de censura. Segundo Fagundes, censor durante o período da Ditadura, deveria sofrer veto de publicação ou divulgação a obra que:

I) ATENTE CONTRA A SEGURANÇA NACIONAL, por conter, potencialmente:

a) incitamento contra a ordem vigente;

b) ofensa à dignidade ou ao interesse pessoal;

c) indução de desprestígio para as forças armadas;

d) instigação contra a autoridade;

e) estímulo à luta de classe;

f) atentado à ordem pública;

g) incitamento de preconceitos étnicos;

h) prejuízo para as boas relações diplomáticas.

II) - FIRA PRINCIPIOS ÉTICOS, por constituir-se, em potencial, em:

a) ofensa ao decoro público;

b) divulgação ou indução aos maus costumes;

c) sugestão, ainda que velada, de uso de entorpecentes;

d) fator capaz de gerar angústia, por retratar a prática de ferocidade;

e) sugestivo à prática de crimes.

III) - CONTRARIE DIREITOS E GARANTIAS INDIVIDUAIS, por representar, potencialmente: 

a) ofensa a coletividade; ou
b) hostilização à religião.
(Fagundes, 1974, p. 144-145).

Em Feliz Ano Novo, no Rio de Janeiro, três jovens pobres encontram-se no apartamento - igualmente pobre - do narrador-personagem, sem dinheiro, sem comida, sem água, fumando maconha e vendo televisão na noite de 31 de dezembro. Decidem sair pela cidade e assaltar uma casa de gente rica em meio à comemoração do Ano Novo. Durante o assalto, matam quatro pessoas, defecam na cama e nos lençóis, comem a ceia, roubam joias e relógios e estupram uma mulher. Retornam ao apartamento e celebram o Ano Novo. Dialoguemos com o objeto, com a voz do narrador-personagem:

\begin{abstract}
Acendemos uns baseados e ficamos vendo a novela. Merda. Mudamos de canal, prum bangue-bangue. Outra bosta.

As madames granfas tão todas de roupa nova, vão entrar o ano novo dançando com braços pro alto, já viu como as branquelas dançam? Levantam os braços pro alto, acho que é pra mostrar o sovaco, elas querem mesmo é mostrar a boceta mas não têm culhão e mostram o sovaco. Todas corneiam os maridos. Você sabia que a vida delas é dar a xoxota por aí?

Pena que não tão dando para gente, disse Pereba. Ele falava devagar, gozador, cansado, doente.

Pereba, você não tem dentes, é vesgo, preto e pobre, você acha que as madames vão dar pra você? Ô Pereba, o máximo que você pode fazer é tocar uma punheta. Fecha os olhos e manda brasa.

Eu queria ser rico, sair da merda em que estava metido! Tanta gente rica e eu fudido. (Fonseca, 2005, p. 14)
\end{abstract}

O fragmento representa a miséria das personagens em franco contraste com a alta sociedade, a desigualdade social cruamente exposta. Além disso, percebemos que os protagonistas são negros pela maneira com que falam das "madames", ou seja, "branquelas", além da identificação de Pereba como negro. A miséria, no Brasil, historicamente assola com maior intensidade a população negra em comparação com a branca, conforme dados de pesquisas do Instituto Brasileiro de Geografia e Estatística, inclusive na atualidade. Nesse diálogo, há elementos que se enquadram nas temáticas passíveis de censura: o uso de drogas, a linguagem obscena e, sobretudo, a saliência da desigualdade social. Recordemos que, para o governo, evidenciar os problemas sociais era uma estratégia comunista para desestabilizar o país e, logo, não deveriam ser retratados, de acordo com Aquino (1999). 
$\mathrm{Na}$ sequência da narrativa, durante o assalto de uma casa em que estavam 25 pessoas comemorando a passagem de ano, depois do primeiro homem ser morto com um tiro no peito:

\footnotetext{
Você aí, levante-se, disse Zequinha. O sacana tinha escolhido um cara magrinho, de cabelos compridos.

Por favor, o sujeito disse, bem baixinho.

Fica de costas para a parede, disse Zequinha.

Carreguei os dois canos da doze. Atira você, o coice dela machucou meu ombro. Apoia bem a culatra senão ela te quebra a clavícula.

Vê como esse vai grudar. Zequinha atirou. O cara voou, os pés saíram do chão, foi bonito, como se ele tivesse dado um salto para trás. Bateu com estrondo na porta e ficou ali grudado. Foi pouco tempo, mas o corpo do cara ficou preso pelo chumbo grosso na madeira. (Fonseca, 2005, p. 20)
}

A "brincadeira" entre os assaltantes consistia em saber se um homem ficaria pregado na parede com uma descarga de uma arma de calibre 12. Escolhem aleatoriamente, sem nenhuma autorreprovação ética, um rapaz e o assassinam, inclusive comentando o narrador-personagem que foi "lindo". Efetivamente, a narrativa choca pela simplicidade crua com que representa 0 assassinato, a violência gratuita, banal e a completa desumanização dos assaltantes. Em nosso entendimento, não efetua uma apologia da violência, como já afirmamos anteriormente, mas instiga à reflexão sobre a banalização da mesma, a desumanização dos indivíduos. Para a censura, de leitura superficial, a passagem pode se enquadrar em instigação ao crime e atentado contra a ordem pública, sendo, pois, passível de censura.

O conto Feliz Ano Novo, reiteremos, constitui-se como um objeto-signo que reflete e refrata o meio ideológico do período militar, sobremaneira a violência urbana. O faz, em nossa compreensão, de modo crítico, articulando forma e conteúdo na produção de um sentido capaz de propiciar a reflexão crítica do leitor acerca da banalização da violência. Ao censor, há temáticas passíveis de censura, desde o uso de palavras obscenas, passando pelo uso de drogas e chagando aos crimes: assassinato, roubo e estupro. Na medida em que as personagens não recebem punição pelos seus atos na narrativa, uma leitura de superfície pode enquadrar o conto como ofensivo à moral e aos bons costumes por instigar ao crime, como, possivelmente, o fez a censura da época, baseando-se nas leis censórias. Da incompreensão da profundidade da 
crítica realizada no universo ficcional do conto, por certo, resultou a censura do mesmo.

\section{REFERÊNCIAS}

ALVES, Maria Helena Moreira. Estado e oposição no Brasil (1964-1984). Tradução de Clóvis Marques. 3. ed. Rio de Janeiro: Vozes, 1985.

AQUINO, Maria Aparecida de. Censura, imprensa, estado autoritário (196878). Bauru: Edusc, 1999.

BAKHTIN, M; VOLOCHÍNOV. Marxismo e filosofia da linguagem: problemas fundamentais do método sociológico da linguagem. Tradução Michel Laud et al. 13. ed. São Paulo: Hucitec, 2012.

CANDIDO, Antonio. Literatura e sociedade: estudos de teoria e história literária. 11. ed. Rio de Janeiro: Ouro sobre Azul, 2010.

COMBLIN, J. A ideologia da Segurança Nacional: o poder militar na América Latina. Tradução Veiga Filho. 2. ed. Rio de Janeiro: Civilização Brasileira, 1978.

FAGUNDES, Coriolano de Loyola Cabral. Censura e liberdade de expressão. São Paulo: Record, 1974.

FONSECA, Rubem. Feliz Ano Novo. Rio de Janeiro: Cia das Letras, 2005.

GASPARI, Élio. A ditadura escancarada. São Paulo: Cia das Letras, 2002.

MEDVIÉDEV, P. O método formal nos estudos literários: introdução crítica a uma poética sociológica. Tradução Sheila Camargo e Ekaterina Américo. São Paulo: Contexto, 2012. 